\title{
"Intermediate Scope" in (Mandarin) Chinese
}

\author{
Ji-yung Kim \\ University of Massachusetts Amherst
}

\section{Introduction}

This paper analyzes the "intermediate scope" readings for two classes of indefinites in Mandarin; these are construals where an indefinite phrase, if analyzed on a par with quantifiers that exhibit scope properties, seems to "scope out" of the syntactic island within which it is contained, while seemingly taking scope under another scopal element.

Mandarin Chinese offers two main classes of indefinites, indefinites headed by a common noun ("N-indefs") and $w h$-indefinites (" $w h$-indefs"). The two classes of indefinites differ from each other in their range of interpretations, in addition to their distinct morphological shapes.

The two classes of indefinites also differ in the conditions under which they allow an intermediate-scope reading. N-indefs, like the English indefinites, show an intermediate-scope reading only in the presence of a bound variable in their restriction, and thus provide strong support for an analysis along the lines of Kratzer 1998, which singles out variable binding as one important source of intermediate reading, rather than the scope-taking properties of the indefinites in question. Wh-indefs, on the other hand, can receive an intermediate scope construal independently of the presence of a bound variable; I argue that they should be analyzed as denoting sets of Hamblin-style alternatives, following Shimoyama 2001

Both of these analyses attribute the intermediate-scope reading of indefinites to something other than scope: in the case of N-Indefs, it is the binding of a variable in their restriction that simulated scope interaction. With $w h$-indefs, it is the alternatives they denote that allow for variation, thus causing the illusion of a scope interaction.

The remainder of the introduction briefly reviews the common assumptions about quantifier scope, defines and presents diagnostics for the particular construal that is the focus of this paper, and introduces the two classes of Mandarin indefinites. $\S 2$ presents the conditions under which an intermediatescope reading is observed with the two classes of indefinites, each of which is analyzed in $\S 3$ and $\S 4$ respectively. $\S 5$ explores the possibility of unifying the separate analyses.

\subsection{The Traditional View}

One common traditional treatment of indefinites is to analyze them as existentially quantified phrases (Russell 1919), or GQ (Generalized Quantifier)versions thereof, as illustrated below: 
(1)
a. some man' $=\lambda \mathrm{P}[\exists \mathrm{x}[\operatorname{man}(\mathrm{x}) \& \mathrm{P}(\mathrm{x})]]$
b. Some man loves every woman.
$b^{\prime}$ '. some man' $(\lambda y$. every woman' $(\lambda x \cdot \operatorname{love}(y, x)))$
$b$ ". every woman' $(\lambda y$. some man' $(\lambda x \cdot \operatorname{love}(x, y)))$

The scope of a (particular occurrence of a) quantifier refers to the material that the quantifier c-commands in the logical representation (May 1977), and for its computation many assume a representation very much alike the logical representations in (1b') and (1b") above to capture readings such as (1b") which do not match the surface word order. Derivation of this level of representation has furthermore been observed to obey constraints similar to the ones involved in the derivation of the surface word order (Lakoff 1970, Rodman 1976, i.a.).

Indefinites, if we are to take the traditional view illustrated above in (1), exhibit very unusual scope properties, unlike quantifiers such as every, which leaves us with the choice of (i) abandoning the traditional view of indefinites, or (ii) abandoning the restrictive view of QR (Quantifier Raising) as a run-of-themill syntactic movement. ${ }^{1}$

In the following section, I introduce one type of indefinite interpretation which seems to belie the assumption that indefinites exhibit normal scope behavior; it is this paper's purpose to show that there is in fact more than one way to account for this construal.

\subsection{The "Intermediate-scope" Dilemma}

In sentences with multiple scopal elements (SE henceforth; Szabolcsi 1997a), indefinites exhibit a range of possible interpretations:

(2) Most linguists have looked at every analysis [that solves some problem]. $\mathrm{SE}_{1} \quad \mathrm{SE}_{2} \quad$ indefinite

a. 'There is some problem, such that most linguists have looked at every analysis that solves that problem.'

b. 'For most linguists, there is some problem, such that they have looked at every analysis that solves that problem.'

c. 'Most linguists have looked at every analysis that solves a problem.'

[Reinhart 1997; Matthewson 1999: 84]

The interpretation of the indefinite paraphrased in (2b) above is what I will be referring to as its "intermediate-scope reading", i.e., a reading where the "scopal" configuration is $\mathrm{SE}_{1}>$ indefinite $>\mathrm{SE}_{2}$.

This interpretation sets indefinites apart in two respects: first, this "scopal" configuration involves the indefinite "scoping" the indefinite some problem out of a complex NP island over the $\mathrm{SE}_{2}$ every analysis. Quantifier Raising therefore does not present itself as an attractive option for the analysis of 
indefinites, at least not in a way that would preserve its attractive restrictiveness (cf. Szabolcsi 1997b; ft 1).

Second, under this reading, the indefinite some problem appears to take scope under the $\mathrm{SE}_{1}$ every linguist, thus distinguishing it from referring expressions (cf. Fodor and Sag 1982), which typically take widest scope. ${ }^{2}$

Thus, the dilemma that the intermediate-scope reading presents is the need for an analysis that can account for the simultaneous "scoping-over" and "scoping-under" properties of indefinites, which show indefinites to pattern neither with quantifiers nor referring expressions. Are we still talking about scope in the usual sense?

\subsection{Mandarin Indefinites}

This section briefly introduces two kinds of Mandarin indefinites that exhibit intermediate-scope readings; their basic form is illustrated below, along with the labels I will use to refer to them throughout this paper:

$$
\begin{aligned}
& \text { a. N-indefs (Noun Indefinites): } \\
& \begin{array}{l}
\text { (yi ge)ren } \\
\text { onecL person }
\end{array}
\end{aligned}
$$

b. Wh-indefs (wh-Indefinites): shei 'who', shenme 'what', etc.

Each kind exhibits significantly different properties from quantifiers and each other; I will argue that the N-Indefs are best accommodated using a choice function approach like Kratzer 1998, while the $w h$-indefs are best explained by a Hamblin-style semantics (Shimoyama 2001).

\section{Chinese $\mathbf{N}$-indefs vs. $W h$-indefs}

This section discusses two sets of data illustrating one main distinction in the interpretation of $\mathrm{N}$-indefs vs. $w h$-indefs. In particular, I focus on the availability of intermediate-scope readings for each kind of indefinite, highlighting the ingredients of the analyses to be discussed in $\S \S 3-4$.

\subsection{Chinese N-indefs: The Importance of Bound Variables}

Chinese N-indefs such as daoyan 'director' below allow for an intermediate scope reading: 


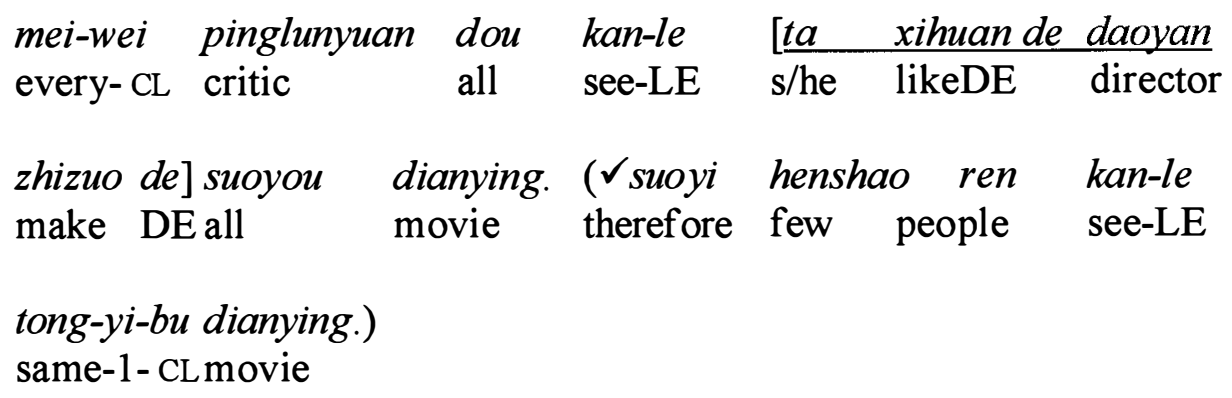

'Every critic saw all the movies that a (possibly different) director $\mathrm{s} / \mathrm{he}$ likes made. (Therefore few people saw the same movie(s).)'

The basic structure of this sentence is as captured by (5a), and the reading we're interested in, as captured by ( $5 b)$ :
a. Skeleton: every critic ... [Rel.Cl ... (a) director $] \ldots$ all movies
b. every critic > (a) director > every movie (in "scopese")

Such a reading is available even with $\mathrm{N}$-indefs in slightly different forms: $y i$-ge daoyan (NUM $+\mathrm{CL}+\mathrm{N}$ ) 'a/one director' or mou-wei daoyan ('certain' $+\mathrm{CL}+\mathrm{N})$.

In (4), the indefinite is itself modified by the embedded modifier '(that) $\mathrm{s} / \mathrm{he}$ likes', which contains the bound variable $t a$ ' $\mathrm{s} / \mathrm{he}$ '. No intermediate-scope reading for this indefinite is available if: (i) there is no embedded modifier such as ta xihuan-de '(that) s/he likes' or (ii) the embedded modifier contains no bound variable. Both of these variations on (4) are illustrated in the example below:

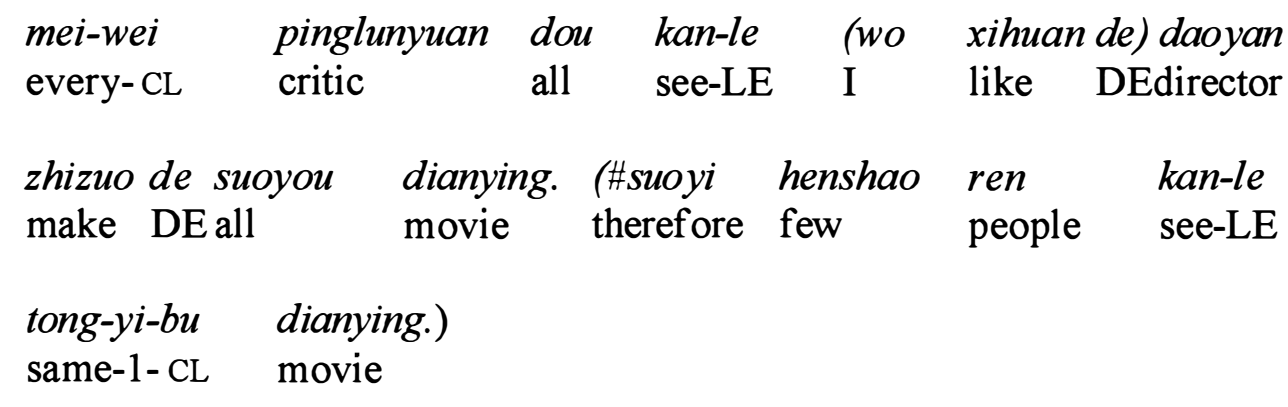

'Every critic saw all the movies that a director (I like) made. (Therefore few people saw the same movie(s)).'

Consultant's comment: “The sequence doesn't make sense. There's only one director, and later you say some people saw something, while others saw others."

As shown by the consultant's comment, the indefinite daoyan 'director' does not exhibit an "intermediate-scope" reading in this example. 
To determine which of the two modifications effected in (6) is responsible for the absence of an "intermediate-scope" reading of the indefinite in (6), it is useful to test items such as bendi-de 'local' as a modifier of indefinite: lexical items such as local, other, different, etc, have been noted to involve a variable (either free or bound) in their interpretation (Mitchell 1986):

$$
\begin{aligned}
& \text { mei-wei pinglunyuan dou kan-le bendi-de daoyan zhizuo } \\
& \text { every-CL critic all see-LE local-DE director make } \\
& \text { de suoyou dianying. (לsuoyi henshao ren kan-le } \\
& \text { DE all movie therefore few people see-LE } \\
& \text { tong-yi-bu dianying.) } \\
& \text { same-1-CL movie }
\end{aligned}
$$

An intermediate-scope reading for the indefinite daoyan 'director' is available in this example, with bendi-de 'local' construed as 'local to critic $x$ '. This shows that the presence of a bound variable in the indefinite's restriction plays an important role in facilitating an intermediate-scope reading, as argued in Kratzer 1998.

\subsection{Chinese Wh-indefs: Bound Variables Don't Matter Any More?!}

Unlike what is observed with $\mathrm{N}$-indefs, the presence of a bound variable does not appear to be a factor with $w h$-indefs:

$$
\begin{aligned}
& \text { haoxiang mei-yi-ben qikan dou jujue chuban liang-pian } \\
& \text { seem every-1-CL journal all refuse publish } 2 \text {-CL } \\
& \text { [Chomskyhan shei yiqi he-xie de ] wenzhang } \\
& \text { C. with who together co-write DE article }
\end{aligned}
$$

The basic structure of this sentence is as illustrated below:

(9) Skeleton: every journal ... 2 [Rel.Cl. ... who/someone ... ] article

There is no modifier for shei 'who/someone' in (8) which could contain a bound variable; yet the intermediate reading for that shei (every journal $>$ someone $>2$ articles) is available. 
Wh-indefs' intermediate-scope readings are subject to a different factor instead: when $\mathrm{SE}_{2}$ is a quantifier such as mei 'every', no intermediate-scope reading is available for shei 'who':
haoxiang
mei-yi-ben
qikan dou
jujue chuban mei-pian
seem
every-1-CL journal all
refuse publish every- $\mathrm{CL}$

[Chomskyhan shei yiqi he-xie de ] wenzhang

C. with who together co-write DE ] article

'It seems that every journal has refused to publish every article that Chomsky has co-written with someone or other.' [Adapted from Lin 2002]

(11) Skeleton: every journal ... every [Rel.Cl. ... who/someone ... ] article

In brief, both kinds of Mandarin indefinites, N-Indefs and wh-indefs, exhibit intermediate-scope readings under different conditions. Since these intermediatescope involve a scopal configuration where the indefinite's "scope" is outside of an island, both of these indefinites defy a QR-analysis in its original conception.

However, the similarity between the two classes of indefinites ends there. The conditions under which they allow for an intermediate-scope construal are very different: $\mathrm{N}$-indefs' intermediate-scope construal hinges on the presence of a bound variable in their restriction, whereas $w h$-indefs' intermediate-scope construal hinges is sensitive to the nature of the SEs involved.

Based on the facts reviewed in this section, the analysis of the two kinds of indefinites we propose will have to satisfy the conditions below:

a. Explain the "intermediate-scope" readings in $(4) /(7),(8)$;

b. Capture absence of island effects in (4)/(7), (8);

c. Treat bound variables, whether or covert, in a parallel manner;

d. Explain why in some cases the presence of a bound variable in the restriction should matter, as shown in (4)-(7), and why sometimes it doesn't, as shown in (8)-(10).

It might already be apparent to the reader that no one analysis could simultaneously satisfy all both sets of desiderata. 


\section{Chinese N-Indefs: A Choice-function Analysis}

\subsection{Intermediate Scope in English}

As shown in $\$ 2.1$, the decisive factor for $\mathrm{N}$-indefs' intermediate scope reading is the presence of a bound variable (covert or overt) in the $\mathrm{N}$-indef's restriction. In this respect, N-Indefs are like the English indefinites discussed in Kratzer 1998 and Schwarzschild 2002:

(13) a. Every professor rewarded every student who read a certain book I had recommended. (\#Because each professor preferred a different book, very few students read the same book.)

b. Every professor $i_{i}$ rewarded every student who read a certain book $\mathrm{s} / \mathrm{he} \mathrm{e}_{\mathrm{i}}$ had recommended. (Because each professor preferred a different book, very few students read the same book.) $)^{1}$

In fact, these are the crucial set of data that set apart Kratzer's (1998) choice function analysis from Reinhart 1997/Winter 1997, which do not attribute a special role to bound variables in an indefinite's restriction.

\subsection{Choice Function Basics}

Choice functions are functions which assign to a non-empty set in its domain a member of that set:

$$
\begin{aligned}
& \mathrm{A}=\{a\} ; \quad \mathrm{f}(\mathrm{A})=a \\
& \mathrm{~B}=\{b, c, d\} ; \mathrm{f}(\mathrm{B})=b(c \text { and } d \text { are also possible values })
\end{aligned}
$$

Unlike Reinhart 1997/Winter 1997, where existential quantification over a choice function is employed to derive the various "scope" readings of indefinites such as the ones illustrated in (2), Kratzer 1998 leaves the choice function variable $\mathrm{f}$ as a free variable (i.e., it is not in the scope of any scopal element); $\mathrm{f}^{\prime} \mathrm{s}$ value is supplied by the context, i.e., in the default case, something like the speaker's intended reference. Let's start with this more restrictive view of choice functions; the discussion to follow will show that this view is quite sufficient to explain the readings observed in the previous section, without accidentally getting us readings that do not exist.

Beside the explicit argument provided by the descriptive content of the noun, Kratzer (1998) posits an implicit variable argument for the choice function; e.g., we may choose to represent the speaker's inference by writing out a free variable ("sp" below) as an argument of the choice function:

a. A certain man walked in. 
b. walk-in(f( $s p$, man $))$, where $\mathrm{f}(s p$, man) selects from the set of men the one that, e.g., the speaker has in mind, or saw, etc.

[Adapted from Chierchia 2001: 54]

The same mechanism captures what appears to be the wide scope reading of an indefinite, as shown for (13a), repeated below:

(13a) Every professor rewarded every student who read a certain book I had recommended.

$$
\begin{aligned}
& \forall x[\operatorname{prof}(x) \rightarrow[\forall y[\operatorname{student}(y) \& \operatorname{read}(y, \mathrm{f}(s p, \text { book } s p \text { recommended })) \rightarrow \\
& \operatorname{reward}(x, y)]]]
\end{aligned}
$$

When the indefinite's restriction doesn't contain a bound variable, the value returned by the choice function doesn't vary with members of the $\mathrm{SE}_{1}$ 's restriction: $\mathrm{f}(s p$,book $s p$ recommended) above picks out from the set of books that the speaker recommended the one that the speaker has in mind.

\subsection{How Bound Variables Help Intermediate-scope Readings}

When the choice function's implicit argument is a bound variable, intermediatescope readings emerge:

(13b) Every professor rewarded every student who read a certain book s/he had recommended.

$$
\begin{aligned}
& \forall x[\operatorname{prof}(x) \rightarrow[\forall y[\operatorname{student}(y) \& \operatorname{read}(y, \underline{\mathrm{f}(x, \text { book } x \text { recommended }))} \\
& \rightarrow \operatorname{reward}(x, y)]]]
\end{aligned}
$$

The value returned by the choice function can vary with members of the $\mathrm{SE}_{1}$ 's restriction: $\mathrm{f}(x$,book $x$ recommended $)$ above picks out from the set of books that $x$ recommended one relativized to $x$.

An alternate way to represent the intermediate-scope reading illustrated in

$$
\begin{aligned}
& \forall x[\operatorname{prof}(x) \rightarrow[\forall y[\operatorname{student}(y) \& \operatorname{read}(y, \underline{\mathrm{f}(s p, \text { book } x \text { recommended })) \rightarrow} \\
& \operatorname{reward}(x, y)]]]
\end{aligned}
$$

As long as the restriction of the indefinite includes a bound variable as in (13b), the value returned by the choice function can vary with members of the $\mathrm{SE}_{1}$ 's restriction even when the choice function's first argument is not a bound variable: $\mathrm{f}(s p$,book $x$ recommended) still has to pick from the set of books that $x$ recommended.

Now re-examine (13a): what happens when a choice function chooses from a set which does not contain a bound variable, as in (13b), but its first implicit argument is a bound variable, as was the case in (17)? 
(13a) Every professor rewarded every student who read a certain book I had recommended.

$$
\begin{aligned}
& \forall x[\operatorname{prof}(x) \rightarrow[\forall y[\operatorname{student}(y) \& \operatorname{read}(y, \mathrm{f}(x, \text { book } s p \text { recommended })) \rightarrow \\
& \operatorname{reward}(x, y)]]]
\end{aligned}
$$

$\mathrm{f}(x$, book $s p$ recommended) picks out from the set of books that the speaker recommended the one relativized to $x$; that would require a natural function connecting professors with books I recommended. But since there aren't enough clues provided for such a function, such a construal is very marginal for this sentence.

Items such as bendi-de 'local' in (7), partially reproduced below, involve in their construal an implicit variable, which could be free or bound (Mitchell 1986); therefore the intermediate scope reading in (7) can be analyzed on a par with (13b), like (17) and (18):

$$
\begin{array}{llllll}
\text { mei-wei pinglunyuan } & \text { dou } & \text { kan-le bendi-de daoyan } & \text { zhezuo } \\
\text { every- CL critic } & \text { all } & \text { see-LE } & \text { local-DE director make }
\end{array}
$$
de suoyou
dianying.
DE all
movie

'Every critic saw all the movies that a (possibly different) local director made.'
a. $\forall x[\operatorname{critic}(x) \rightarrow[\forall y[\operatorname{movie}(y) \& \operatorname{made}(\mathrm{f}(x, \operatorname{director}$ local to $x), y) \rightarrow$ $\operatorname{saw}(x, y)]]]$
b. $\forall x[\operatorname{critic}(x) \rightarrow[\forall y[\operatorname{movie}(y) \& \operatorname{made}(\mathrm{f}(s p$, director local to $x), y) \rightarrow$ $\operatorname{saw}(x, y)]]]$

Both formulations give rise to an "intermediate-scope" reading, without any scoping. Instead, as shown here, the formulations attribute a significant role to bound variables in the indefinites' restriction. Therefore, this approach's extension to $w h$-indefs, which we saw in $\$ 2.2$ are completely indifferent to the presence of bound variables, can't be straightforward; we need an alternate analysis.

\section{Chinese $W h$-indefs: A Hamblin-style Semantics}

\subsection{A Hamblin-style Alternative Approach to Chinese Wh-indefs}

Beside the pseudo-existential interpretation we observed $w h$-indefs to receive in (8)-(10), it is a well-known fact that wh-indefs such as shenme (in bold below) 
can have a range of interpretations, as discussed in Huang 1982, Cheng 1994, Lin 1996, i.a.:

a. Zhangsan mai shenme

$Z$. buy what

'What will Zhangsan buy?'

b. Zhangsan shenme dou mai

$Z$. what all buy

'Zhangsan buys all kinds of things.'

Such versatility of interpretation is strongly reminiscent of the Japanese whphrases, for which Shimoyama 2001 proposes an analysis uniform throughout the range of possible readings. This proposal is further pursued in Kratzer and Shimoyama 2002 and Kratzer 2003. This is the analysis we adopt below.

\subsection{Sample Derivation: Deriving the Interrogative Reading of (2Ia)}

Hamblin 1973 proposes that question words (in English) can be analyzed as denoting sets of individuals. Extending this view to $w h$-indefs, we assume:

$$
[[\text { shenme }]]^{\mathrm{w}, \mathrm{g}}=\{\mathrm{x} \text { : thing }(\mathrm{x})(\mathrm{w})\} \text { (the set of all things) }
$$

In contrast, for other non-wh-lexical items, we assume that they simply denote singleton sets. For instance, a predicate such as mai 'buy' denotes a singleton set of functions mapping individuals to properties (we will not discuss the tense and aspect morphemes, for simplicity):

$$
[[\mathrm{mai}]]^{\mathrm{w}, \mathrm{g}}=\left\{\lambda x \lambda y \lambda w^{\prime} \cdot \operatorname{buy}(\mathrm{x})(\mathrm{y})\left(\mathrm{w}^{\prime}\right)\right\}
$$

These predicates are put together with (nonsingleton) set-denoting expressions according to the following rule:

(24) Hamblin Functional Application

If $\alpha$ is a branching node with daughters $\beta$ and $\gamma$, and $[[\beta]]^{\mathrm{w}, \mathrm{g}} \subseteq \mathrm{D}_{\mathrm{\sigma}}$ and $[[\gamma]]^{\mathrm{w}, \mathrm{g}} \subseteq \mathrm{D}_{<_{\sigma}>}$, then $[[\alpha]]^{\mathrm{w}, \mathrm{g}}=\left\{\mathrm{a} \in \mathrm{D}_{\mathrm{r}}: \exists b \exists c\left[\mathrm{~b} \in[[\beta]]^{\mathrm{w}, \mathrm{g}} \& \mathrm{c} \in[[\gamma]]^{\mathrm{w}, \mathrm{g}} \&\right.\right.$ $\mathrm{a}=\mathrm{c}(\mathrm{b})]\} . \quad$ [Adapted from Kratzer and Shimoyama 2002: 6]

Therefore, the result of composing mai 'to buy' with the $w h$-indef shenme 'what' goes as follows:

$$
\begin{aligned}
& {[[\text { mai shenme }]]^{\mathrm{w}, \mathrm{g}}} \\
& =\left\{\mathrm{f} \in \mathrm{D}_{<e, s t}: \exists x\left[\operatorname{thing}(x)(\mathrm{w}) \& \mathrm{f}=\lambda \mathrm{y} \lambda \mathrm{w}^{\prime} . \operatorname{buy}(\mathrm{x})(\mathrm{y})\left(\mathrm{w}^{\prime}\right)\right]\right\}
\end{aligned}
$$


This is a set of properties of the form $\left\{\lambda y \lambda w^{\prime} \cdot \operatorname{buy}(a)(y)\left(w^{\prime}\right), \lambda y \lambda w^{\prime} \cdot b u y(b)(y)\left(w^{\prime}\right)\right.$, $\lambda y \lambda w^{\prime}$.buy $\left.(c)(y)\left(w^{\prime}\right), \ldots\right\}$ (where $a, b, c$ are things in $w$ ). Adding the external argument Zhangsan to this, we obtain:

$$
\begin{aligned}
& {[[\text { mai shenme }]]^{\mathrm{w}, \mathrm{g}}(\text { Zhangsan })} \\
& =\left\{\mathrm{p}: \exists x\left[\operatorname{thing}(x)(\mathrm{w}) \& \mathrm{p}=\lambda \mathrm{w}^{\prime} \cdot \operatorname{buy}(\mathrm{x})(\text { Zhangsan })\left(\mathrm{w}^{\prime}\right)\right]\right\}
\end{aligned}
$$

Informally put, this is the set of propositions of the form ' $Z$. bought $a$ ', ' $Z$. bought $b$ ', ' $Z$. bought c', ... (where $a, b, c$ are individuals in $w$ ).

This is all we need to get at the question reading illustrated in (21a), under the widely accepted view that questions denote sets of propositions (Hamblin 1973). ${ }^{4}$ Under this proposal, the interpretation of the $w h$-indef can thus be explained without resort to a displacement strategy; again, it is already apparent that the intermediate-scope reading under this approach will turn out to have little to do with the scope properties of the $w h$-indefs.

\section{3. (Partial) Sample Derivation 2: Absence of Intermediate Scope}

(10), whose skeleton is repeated below from $\$ 2.2$, does not exhibit an intermediate scope reading for the $w h$-indef:

(10) Skeleton: every journal ... every $[$ Rel.Cl. ... who/someone ... ] article

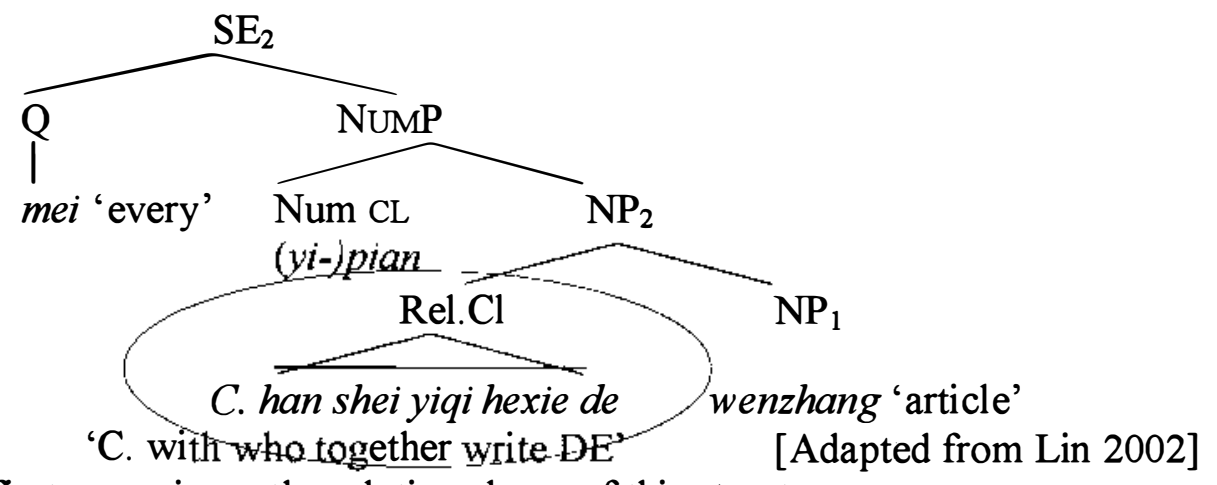

Let's first zoom in on the relative clause of this structure:

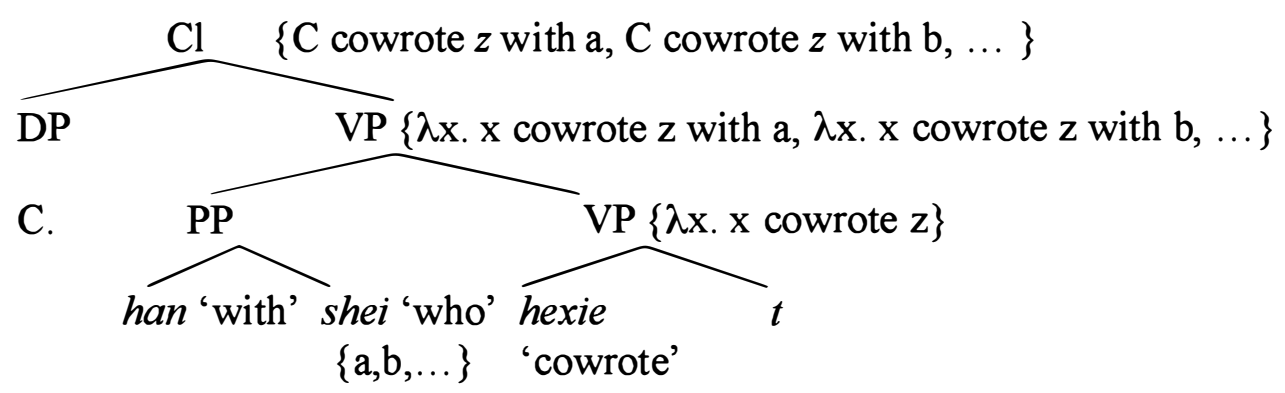

The $\mathrm{Cl}$ (ause) represented in (28) is a relative clause, which we interpret using the following Hamblinized version of predicate abstraction (cf. Heim and Kratzer 1997): 
(29) Predicate Abstraction: If $\alpha$ is a branching node whose daughters are an index $\mathrm{i}$ and $\beta$, where $[[\beta]]^{\mathrm{w}, \mathrm{g}} \subseteq \mathrm{D}_{\sigma}$, then $[[\alpha]]^{\mathrm{w}, \mathrm{g}}=\{\mathrm{f}: \mathrm{f} \in \mathrm{D}<\mathrm{e} \sigma>\& \forall \mathrm{a}[\mathrm{f}(\mathrm{a})$ $\left.\left.\in[[\beta]]^{\mathrm{w}, g[a / \mathrm{i}]}\right]\right\}$ [Kratzer and Shimoyama 2002: 8]

Basically, this rule abstracts over the indexed variable inside a formula:

$$
\begin{aligned}
& {[[R e l . C l]]^{\mathrm{w}, \mathrm{g}}} \\
& =\left\{\mathrm{f}: \mathrm{f} \in \mathrm{D}_{\mathrm{ess}} \& \forall \mathrm{a}\left[\mathrm{f}(\mathrm{a}) \in\left\{\mathrm{p}: \exists \mathrm{x}\left[\mathrm{human}(\mathrm{x})(\mathrm{w}) \& \mathrm{p}=\lambda \mathrm{w}^{\prime} \cdot \operatorname{cowrote}(\mathrm{a})(\mathrm{x})(\mathrm{C})\left(\mathrm{w}^{\prime}\right)\right]\right\}\right]\right\} \\
& =\left\{\mathrm{f}: \exists \mathrm{x}\left[\operatorname{human}(\mathrm{x})(\mathrm{w}) \& \mathrm{f}=\lambda \mathrm{y} \lambda \mathrm{w}^{\prime} \cdot \operatorname{cowrote}(\mathrm{y})(\mathrm{x})(\mathrm{C})\left(\mathrm{w}^{\prime}\right)\right]\right\}
\end{aligned}
$$

Informally put, this is the set of properties of being something Chomsky cowrote with a, of being something Chomsky cowrote with $b$, of being something Chomsky cowrote with c, .... . Putting together the relative clause (30) and the $\mathrm{N}(\mathrm{P})$ wenzhang 'article', using Predicate Modification (cf. Heim and Kratzer 1997), we obtain:

$$
\begin{aligned}
& {\left[\left[\mathrm{NP}_{2}\right]\right]^{\mathrm{wg}}} \\
& =\left\{\mathrm { f } f \in \mathrm { D } _ { \text { <est } } \& \forall \mathrm { y } \left[\mathrm { f } ( \mathrm { y } ) \in \left\{\mathrm{p}: \exists \mathrm{x}\left[\operatorname{human}(\mathrm{x})(\mathrm{w}) \& \mathrm{p}=\lambda \mathrm{w}^{\prime} \cdot \operatorname{article}(\mathrm{y})\left(\mathrm{w}^{\prime}\right) \&\right.\right.\right.\right. \\
& \left.\left.\left.\left.\quad \operatorname{cowrote}(\mathrm{y})(\mathrm{x})(\mathrm{C})\left(\mathrm{w}^{\prime}\right)\right]\right\}\right]\right\} \\
& =\left\{\mathrm{f}: \exists \mathrm{x}\left[\operatorname{human}(\mathrm{x})(\mathrm{w}) \& \mathrm{f}=\lambda \mathrm{y} \lambda \mathrm{w}^{\prime} \cdot \operatorname{article}(\mathrm{y})\left(\mathrm{w}^{\prime}\right) \& \operatorname{cowrote}(\mathrm{y})(\mathrm{x})(\mathrm{C})\left(\mathrm{w}^{\prime}\right)\right]\right\}
\end{aligned}
$$

Informally paraphrased, this is the set of properties of being an article by Chomsky with a, of being an article by Chomsky with b, of being an article by Chomsky with $\mathrm{c}, \ldots$...

For the moment, we will ignore the classifier (which is common to both the QP formation and the NumP formation), and add the quantifier mei 'every', whose contribution I assume to be parallel to that of a Hamblin version of a universal (generalized) quantifier (32), or the Mandarin equivalent of the (32') as suggested in Lin 1998:

$$
\begin{aligned}
{[[\forall \alpha]]^{\mathrm{w}, \mathrm{g}}=\left\{\lambda \mathrm { P } \lambda \mathrm { w } \cdot \forall \mathrm { a } \left[\mathrm{a} \in[[\alpha]]^{\mathrm{w}, \mathrm{g}} \rightarrow\right.\right.} & \mathrm{P}(\mathrm{a})(\mathrm{w})=1]\} \\
& {[\text { Kratzer and Shimoyama 2002: 8] }}
\end{aligned}
$$

$$
[[\mathrm{mei}]]^{\mathrm{w}, \mathrm{g}}=\left\{\lambda \mathrm{P} \lambda \mathrm{w} . \cup[[\mathrm{P}]]^{\mathrm{w}, \mathrm{g}}\right\}
$$

As shown in both (32) and (32'), there is nothing for $\mathrm{SE}_{1}$ to distribute over: either way, the result of applying mei 'every' to the $\mathrm{NP}_{2}$ denotation in (31) is a singleton set. Putting this together with the rest of the sentence, we get a reading that can be paraphrased as follows: 'Every journal rejected every article by C. \& anyone.', and we do not get any intermediate-scope reading for shei 'who'.

Worth noting here is the fact that the alternatives are "caught" by (i.e., the set of alternatives stops expanding because of) $m e i$ 'every', and the reasons for such a cap on their expansion are strictly semantic, rather than syntactic; the unavailability of an intermediate-scope reading for the $w h$-indef here has nothing to do with any syntactic island effect. ${ }^{5}$ 


\section{4. (Partial) Sample Derivation 3: Intermediate Scope Reading Without Bound Variables}

(8), whose skeleton is repeated below from $\S 2.2$, allows an intermediate-scope construal for the $w h$-indef shei:

(8) Skeleton: every journal ... $2[$ Rel.Cl. ... who/someone ... ] article

I follow Lin 2002 in analyzing Chinese numerals such as liang 'two' as cardinal modifiers (Milsark 1974, Partee 1987, Diesing 1992, i.a.).

The computation proceeds the same as shown above in (30)-(31); we just need to combine (31) with the denotation of the numeral liang 'two', as a result of which we get a reading that can be paraphrased as the following:

(33) \{two/pair of articles by Chomsky and a, two/pair of articles by C. and b, two/ pair of articles by Chomsky and $c, \ldots\}$

The result of putting this together with the rest of the sentence is the following:

(34) Every journal rejected a member of $\mathrm{A}: \mathrm{A}=$ \{two articles by $\mathrm{C}$. and a, a two articles by $\mathrm{C}$. and b, two articles by $\mathrm{C}$. and $\mathrm{c}, \ldots\}$

Since the alternatives are still available, it is possible for C.'s co-author to vary from journal to journal. It is this possibility that creates the effect of an intermediate-scope reading for the indefinite shei 'who', again without anything resembling scoping.

This particular derivation also shows that given a Hamblin-style semantics for $w h$-indefs, their island-insensitivity falls out naturally: as shown in (33)-(34), the alternatives stay available past the (complex NP)-island (cf. Shimoyama 2001) Note again that no movement is necessarily involved in the interpretation of shei 'who', or the constituents beyond it, unlike what was proposed in Nishigauchi 1986 , i.a, in the account of island-insensitivity. ${ }^{6}$

\section{Discussion}

I have shown in the previous sections the empirical bases for a split approach to the Mandarin N-indefs and $w h$-indefs. It is however conceivable that this split approach does not strike one as theoretically elegant or even desirable. This section explores the possibility of bringing together the two analyses; it will become evident that such unification is only possible at the expense of common theoretical assumptions as well as explanatory adequacy. 


\subsection{Bringing the Choice Function Approach Around}

Schwarzschild 2002 proposes a way that preserves both the traditional assumptions concerning indefinites as quantifiers and observations about the behavior of quantifiers. He assumes that indefinites are interpreted as existentially quantified phrases, and that their scope properties parallel that of other quantifiers in obeying restrictions on islands.

The exceptional "scope" behavior of indefinites discussed in $\$ 2$ must therefore be attributed to something else; Schwarzschild 2002 proposes that such behavior follows from the domain restriction imposed by the existential quantifier introduced by the indefinite (or its determiner). In particular, the domain restriction in the exceptional cases is limited to a singleton set, thus allowing minimal variation of reference in the scope of another quantifier; the "scopeunder" properties observed in intermediate-scope reading contexts are the result of variable binding, as assumed in Kratzer 1998.

Kratzer 1998 and Schwarzschild 2002 thus both concur that an account of indefinites' intermediate-scope reading need not resort to any scoping mechanism, and in fact, is due to the binding of the variables in the indefinites' restriction. Considering this fact, choice functions can be regarded as a descriptive equivalent for capturing the unusual behavior of indefinites, rather than a separate analytic tool on its own.

The choice-function analysis for $\mathrm{N}$-indefs discussed in $\S 3$ can thus be subsumed under independent assumptions (e.g., quantifier domain restriction). The remaining question is whether the other half of the split analysis can also be brought around in a similar fashion.

\subsection{Is a Unified Approach to Both Indefinite Classes Possible?}

I showed in $\$ 2$ how distinct the conditions are that facilitate the intermediatescope reading of indefinites. The discussion in $\$ \S 3-4$ further highlighted the properties of each of the approaches proposed for each class of indefinites, in their most restrictive form.

Both the choice function analysis and the Hamblin-style analysis concur that no island-sensitivity is predicted with indefinites, unlike quantifiers, whose behavior indicate sensitivity to syntactic restrictions. Both of the analyses also concur that what seems like scopal behavior of an indefinite is in fact something else; with the choice-function analysis, it is variable-binding, in the case of the Hamblin-style approach, it is the availability of the multiple alternatives, that create the illusion of scoping.

Given these commonalities, it is conceivable that the restrictiveness of one of the approaches could be relaxed, so as to further unify the treatment of the indefinites discussed in this paper.

As shown in Lin 2002, where only intermediate-scope readings such as those illustrated in $\$ 2.2$ are discussed, some of the properties of $w h$-indefinites could be subsumed with the $\mathrm{N}$-indefs, supposing that we adopt a different version 
of choice function analysis, such as that of Chierchia 2001, where existential closure over choice functions is assumed in certain contexts.

In fact, as Lin 2002 points out, the choice function approach in Reinhart 1992 was intended to handle the interpretation of $w h$-in-situ (in English). This may seem like further justification for applying a single choice function analysis to both classes of indefinites.

Lin 2002 however faces a dilemma when it comes to the $\mathrm{N}$-indefs discussed in $\$ 2.1$ : it is impossible to modify a choice function approach in such a way that it would allow consideration for bound variables in some situations (Nindefs) but not others ( $w h$-indefs).

Having established this point, it is also evident that the Hamblin-style approach can't be extended to accommodated the $\mathrm{N}$-indefs either, since $\mathrm{N}$-indefs do not exhibit quite the range of readings as $w h$-indefs (as illustrated in $(21 \mathrm{a} / \mathrm{b})$ ), and again, since $\mathrm{N}$-indefs exhibit intermediate-scope readings under very different conditions from $w h$-indefs.

Given the above considerations, the split analysis indeed seems to be the only possibility. It is possible to make sense of the dichotomy of analyses in the following way: $\mathrm{N}$-indefs are a class of expressions used when the narrowest possible reference is intended, and $w h$-indefs are a class of expressions used when the entirety of the set given by the restriction is at issue, as with free choice or polarity items.

\section{Concluding Remarks}

In this paper, I discussed and analyzed the intermediate-scope readings of two classes of Mandarin indefinites. We saw that Mandarin $\mathrm{N}$-indefs and $w h$-indefs differ not only in terms of their range of interpretations, but also in terms of the conditions under which an intermediate-scope construal is possible. On the one hand, $\mathrm{N}$-indefs were shown to require a bound variable in their restriction for an intermediate-scope construal. It was therefore crucial that the proposal give these bound variables sufficient weight; I identified Kratzer 1998 as such a proposal, and showed how it explains the plausible and the implausible readings.

On the other hand, wh-indefs were shown to exhibit an intermediate-scope reading depending on $\mathrm{SE}_{2}$, regardless of the presence of a bound variable in their restriction. I therefore resorted to an alternative proposal, i.e., a Hamblin-style alternative semantics, which captured the relevant readings.

Under both analyses, the exceptional behavior of indefinites is no longer characterized as (quantifier) scope: in the case of N-Indefs, it is the binding of a variable in their restriction that simulated scope interaction; with $w h$-indefs, it is the alternatives that the indefinites (or the constituents containing them) denote that allowed for variation, thus creating the illusion of a scope interaction.

With these two separate analyses in place, we can explain the different properties of the sorts of indefinites in the contexts we looked at, in addition to some of their properties in other contexts. The Kratzer-style choice function approach highlights the parallel between the English indefinites as discussed in 
Kratzer 1998 and Schwarzschild 2002, i.a., and Mandarin N-indefs, while the Hamblin-style alternative semantics highlights the versatility of $w h$-indefs, a property shared by Japanese $w h$-expressions as analyzed in Shimoyama 2001 and the Bengali $k$-words discussed in Ramchand 1997.

\section{Endnotes}

* This work evolved from a manuscript entitled "Pseudo-scope in Chinese", which examined the "intermediate-scope" reading of Mandarin N-indefs, with the findings as reported in $\S 2.1$ of this paper. Jowang Lin's presentation at GLOW in Asia 2002 (Tsing-hua University, Taiwan) on the intermediate-scope reading of $w h$-indefs sparked the question of why the conditions for the two classes of indefinites should be so distinct and thus inspired the work in its present form. Previous versions of this work were presented at the University of Ottawa and SALT XIII (Seattle, WA); audiences at both of these venues are gratefully acknowledged. I thank Jowang Lin for sharing details of his work and discussion, and (Ling) Zhao laoshi, Melody Zhang, Jiaying Shen, and Linton Wang for additional judgment help. I am also very grateful to Barbara $\mathrm{H}$. Partee and Angelika Kratzer for helpful discussion of this work; the usual disclaimers apply.

${ }^{1}$ In fact, this is the position adopted by many of the contributions in Szabolcsi 1997b, which assume that a syntactic movement akin to the commonly assumed $\mathrm{QR}$ is relativized to different quantifier classes.

${ }^{2}$ At least such is the contention in Fodor and Sag 1982, which Abusch 1994 partially counters with examples of intermediate-scope reading. It is however observed that an intermediate-scope construal is also possible with definite NPs as well (Bende-Farkas and Kamp 2001, i.a.).

3 Abusch's (1994) example as adapted by Matthewson (2000), with the continuation added by JYK; continuations such as this as easy diagnostics for intermediate-scope construals is suggested in von Fintel 1995.

${ }^{4}$ The question of whether a question operator is still necessary is discussed in detail in Kim (in preparation).

${ }^{5}$ According to Lin 2002, an intermediate-scope reading becomes more easily available if the relative clause precedes the quantifier, which is also a possibility in Mandarin. It is not difficult to see how the Hamblin-style semantics would account for this difference: assuming a straightforward surface order-LF mapping, the relative clause merges after the quantifier mei 'every' does, and thus the alternatives can keep expanding beyond $\mathrm{SE}_{2}$ in (27). I do not pursue this issue further in this paper, as it would necessitate a full account of the precise structure/interpretation mapping of noun phrases in Mandarin, an issue well beyond the scope of this paper.

6 This is not to say that the Hamblin-style semantics precludes movement for all instances of $w h$-indef interpretation. Some cases where (covert) movement might be necessary, even under this approach, are discussed in Kratzer and Shimoyama 2002 and Kim (in preparation). [Many thanks to Ken Shan for bringing up this point at the presentation] 


\section{References}

Abusch, Dorit. 1994. The scope of indefinites. Natural Language Semantics 2:83135.

Bende-Farkas, Agnes, and Hans Kamp. 2001. Indefinites and binding: From specificity to incorporation. Ms., Lectures notes, ESSLLI 13,Helsinki, Finland.

Cheng, Lisa L.-S. 1994. Wh-words as polarity items. In Chinese Languages and Linguistics II, ed. Ren-kui Li, 614-640. Taipei: Academia Sinica.

Chierchia, Gennaro. 2001. A puzzle about indefinites. In Semantic Interfaces: Reference, Anaphora and Aspect, ed. Carlo Cecchetto, Gennaro Chierchia and Maria Teresa Guasti, 51-89. Stanford: CSLI Publications.

Diesing, Molly. 1992. Indefinites. Cambridge: MIT Press.

Fodor, Janet D, and Ivan Sag. 1982. Referential and quantificational indefinites. Linguistics and Philosophy 5:355-398.

Hamblin, C. L. 1973. Questions in Montague English. Foundations of Language 10:41-53.

Heim, Irene, and Angelika Kratzer. 1997. Semantics in Generative Grammar. Oxford: Blackwell Publishers.

Huang, C.-T. James. 1982. Logical Relations in Chinese and the Theory of Grammar. Doctoral thesis, MIT.

Kim, Ji-yung. In preparation. Scope: The View from Indefinites. Doctoral thesis, University of Massachusetts Amherst.

Kratzer, Angelika. 1998. Scope or pseudo-scope? Are there wide-scope indefinites? In Events in Grammar, ed. Susan Rothstein, 163-196. Dordrecht: Kluwer.

Kratzer, Angelika, and Junko Shimoyama. 2002. Indeterminate Pronouns: The View from Japanese. Ms., Paper presented at the 3rd Tokyo Conference on Psycholinguistics.

Kratzer, Angelika. 2003. Indefinites and functional Heads: From Japanese to Salish. Ms., Paper presented at SALT XIII.

Lakoff, George. 1970. Repartee. Foundations of Language 6:389-422.

Lin, Jo-wang. 1996. Polarity Licensing and Wh-Quantification in Chinese. Doctoral thesis, University of Massachusetts Amherst.

Lin, Jo-wang. 1998. Distributivity in Chinese and its implications. Natural Language Semantics 6:201-243.

Lin, Jo-wang. 2002. Choice functions and the interpretation of indefinite polarity wh-phrases. Ms.Paper presented at GLOW in Asia 2002. Hsin-chu, Taiwan.

Matthewson, Lisa. 1999. On the interpretation of wide-scope indefinites. Natural Language Semantics 7:79-134.

May, Robert. 1977. The Grammar of Quantification. Doctoral thesis, MIT.

Milsark, G. 1974. Existential Sentences in English. Doctoral thesis, MIT.

Mitchell, J. 1986. The Formal Semantics of Point of View. Doctoral thesis, University of Massachusetts Amherst. 
Nishigauchi, Taisuke. 1986. Quantification in the Theory of Grammar. Doctoral thesis, University of Massachusetts Amherst.

Partee, Barbara H. 1987. Noun phrase interpretation and type-shifting principles. In Studies in Discourse Representation Theory and the Theory of Generalized Quantifiers, ed. J. Groenendijk. Dordrecht: Foris.

Ramchand, Gillian C. 1997. Questions, polarity and alternative semantics. In Proceedings of the North East Linguistic Society 27, ed. Kiyomi Kusumoto, 383-396. Amherst: GLSA Publications.

Reinhart, Tanya. 1992. Wh-in-situ: An apparent paradox. In Proceedings of the Eight Amsterdam Colloquium, ed. Paul Dekker and Martin Stokhof. Amsterdam: ILLC.

Reinhart, Tanya. 1997. Quantifier scope: How labor is divided between QR and choice functions. Linguistics and Philosophy 20:335-397.

Rodman, Robert. 1976. Scope phenomena, movement transformations, and relative clauses. In Montague Grammar, ed. Barbara H. Partee. New York: Academic Press.

Russell, Bertrand. 1919. Introduction to Mathematical Philosophy. London: Allen and Unwin.

Schwarzschild, Roger. 2002. Singleton indefinites. Journal of Semantics 19:289314.

Shimoyama, Junko. 2001. Wh-constructions in Japanese. Doctoral thesis, University of Massachusetts Amherst.

Szabolcsi, Anna. 1997a. Strategies for scope taking. In Ways of Scope Taking, ed. Anna Szabolcsi, 109-154. Dordrecht: Kluwer.

Szabolcsi, Anna ed. 1997b. Ways of Scope Taking. Dordrecht: Kluwer.

von Fintel, Kai. 1995. Lecture notes for the seminar on context-dependency. Ms.MIT.

Winter, Yoad. 1997. Choice functions and the scopal semantics of indefinites. Linguistics and Philosophy 20:399-467.

Kim, Ji-yung

Department of Linguistics

South College 226

University of Massachusetts Amherst

Amherst, MA 01003

kjyung@linguist.umass.edu

http://www-unix.oit.umass. edu/ kjyung/myweb/ 